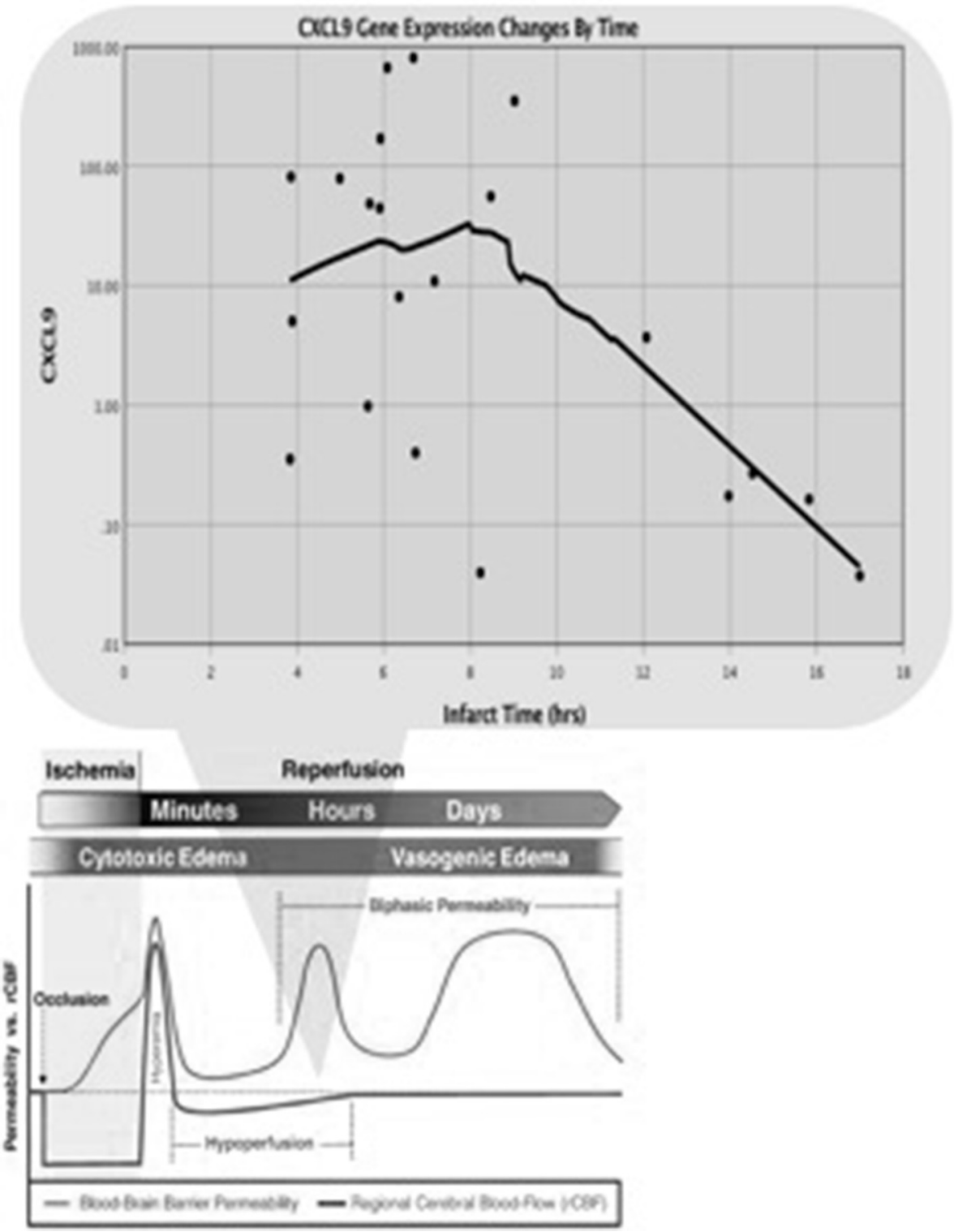

Abstract 0-004 Figure 1 Graph demonstrating time-dependent differential gene expression of CXCL9 in distal vs proximal blood sample ( $\mathrm{n}=21$ ). The $y$-axis shows fold-changes in distal expression over proximal expression. Infarct time is defined as Last Known Normal to thrombectomy recanalization moment. The panel below shows these changes mapped to a published timeline of BBB permeability

Disclosures J. Fraser: None. S. Martha: None. L. Collier: None. S. Davis: None. A. Alhajeri: None. S. Grupke: None. K. Pennypacker: None.

\section{O-005 THE IMPACT OF FAILED REPERFUSION ON THE CLINCAL OUTCOMES OF PATIENTS PRESENTING WITH LOW NIHSS LARGE VESSEL OCCLUSION}

F Chin*, M Waqas, H Shallwani, H Rai, E Lewy, A Siddiqui. Endovascular Neurosurgery, SUNY Buffalo, Buffalo, NY

\subsection{6/neurintsurg-2019-SNIS.5}

Introduction The effectiveness of mechanical thrombectomy in patients presenting with a low NIHSS and large vessel occlusion is uncertain. The objective of this study was to compare clinical outcomes of patients with successful (TICI $2 \mathrm{~b} / 3$ ) and failed (TICI 0/2a) reperfusions during endovascular mechanical thrombectomy for low NIHSS large vessel occlusion stroke.

Materials and methods We conducted a retrospective analysis on all patients who underwent stent retriever and/or aspiration thrombectomy between January 2012 to May 2017 at the Gates Vascular Institute in Buffalo, NY. Thirty-one patients with a large vessel occlusion and NIHSS $\leq 6$ were identified. These patients were divided into two groups, those who received TICI $2 b / 3$ recanalization and those who received TICI 0/2a. Demographic, procedural and outcome data was collected. Occurrence of vasospasm, thromboembolic complications, symptomatic hemorrhage, discharge NIHSS, hospital stay and outcome at 90 days were compared between the two groups.

Results Of the 31 thrombectomies, 26 were TICI 2b/3 while 5 were TICI $0 / 2 \mathrm{a}$. The mean age of patients who attained successful reperfusion was $68.35 \pm 11.88$ years with 11 males $(42 \%)$ whereas that of failed patients was $65 \pm 15.20$ years 
with 3 males (60\%). Of the TICI $2 \mathrm{~b} / 3$ patients, there were 7 incidences of vasospasm (27\%), 3 symptomatic intracranial hemorrhages (12\%), 4 hospital deaths (15\%) and 20 favorable outcomes (mRS 0-2 at 90 days) (77\%). In contrast, there were 0 vasospasms, 2 symptomatic intracranial hemorrhages (40\%), 2 hospital deaths (40\%) and only 2 favorable outcomes in the TICI $0 / 2$ a group (40\%). Neither group had any thromboembolic complications. Median (IQR) discharge NIHSS was $2(1-4.75)$ in the TICI $2 \mathrm{~b} / 3$ group compared to 3 (3-40) in the TICI 0/2a group. Both groups shared a median decrease in NIHSS score of 2 post-thrombectomy. Differences between the two groups were not statistically significant.

Conclusion While mild stroke patients with TICI $2 \mathrm{~b} / 3$ reperfusion had better outcomes across the board, the differences were not statistically significant. Mechanical thrombectomy may confer benefits upon mild stroke patients with large vessel occlusion; however, additional research is needed to validate these benefits.

Disclosures F. Chin: None. M. Waqas: None. H. Shallwani: None. H. Rai: None. E. Levy: 1; C; Medtronic US SWIFT PRIME Trials. 2; C; Pulsar Vascular. Advisory Board- Stryker, NeXtGen Biologics, MEDX, Cognition Medical.. 4; C; Intratech Medical Ltd., NeXtGen Biologics.. 6; C; Abbott Vascular for carotid training sessions. A. Siddiqui: 1; C; Cerenovus
LARGE Trial, ARISE II Trial, Medtronic SWIFT PRIME and SWIFT DIRECT Trials, MicroVention FRED Trial \& CONFIDENCE Study, MUSC POSITIVE Trial, Penumbra 3D Separator Trial, COMPASS Trial etc.. 2; C; Amnis Therapeutics, Boston Scientific, Canon Medical Systems USA Inc., Cerebrotech Medical. Systems Inc., Cerenovus, Claret Medical, Corindus Inc., Endostream Medical Ltd etc.. 4; C; Amnis Therapeutics, Apama Medical, BlinkTBI Inc., Buffalo Technology Partners Inc, Cardinal Health, Cerebrotech Medical Systems Inc, Claret Medical, Coggnition Medical, Endostream Medical Ltd etc.

\section{0-006 READMISSION AFTER TREATMENT OF ASYMPTOMATIC CAROTID STENOSIS: A NATIONWIDE READMISSION DATABASE ANALYSIS}

${ }^{1} \mathrm{P}$ Nazari ${ }^{*},{ }^{1} \mathrm{P}$ Golnari, ${ }^{1} \mathrm{R}$ Garcia, ${ }^{1} \mathrm{H}$ Weiss, ${ }^{2} \mathrm{~S}$ Ansari, ${ }^{2} \mathrm{~A}$ Shaibani, ${ }^{2} \mathrm{M}$ Hurley, ${ }^{1} \mathrm{M}$ Potts, ${ }^{1} \mathrm{~B}$ Jahromi. ${ }^{1}$ Neurosurgery, Northwestern University, Chicago, IL; ${ }^{2}$ Radiology, Northwestern University, Chicago, IL

10.1136/neurintsurg-2019-SNIS.6

Introduction Carotid endarterectomy (CEA) and carotid artery stenting (CAS) are two common methods for treating

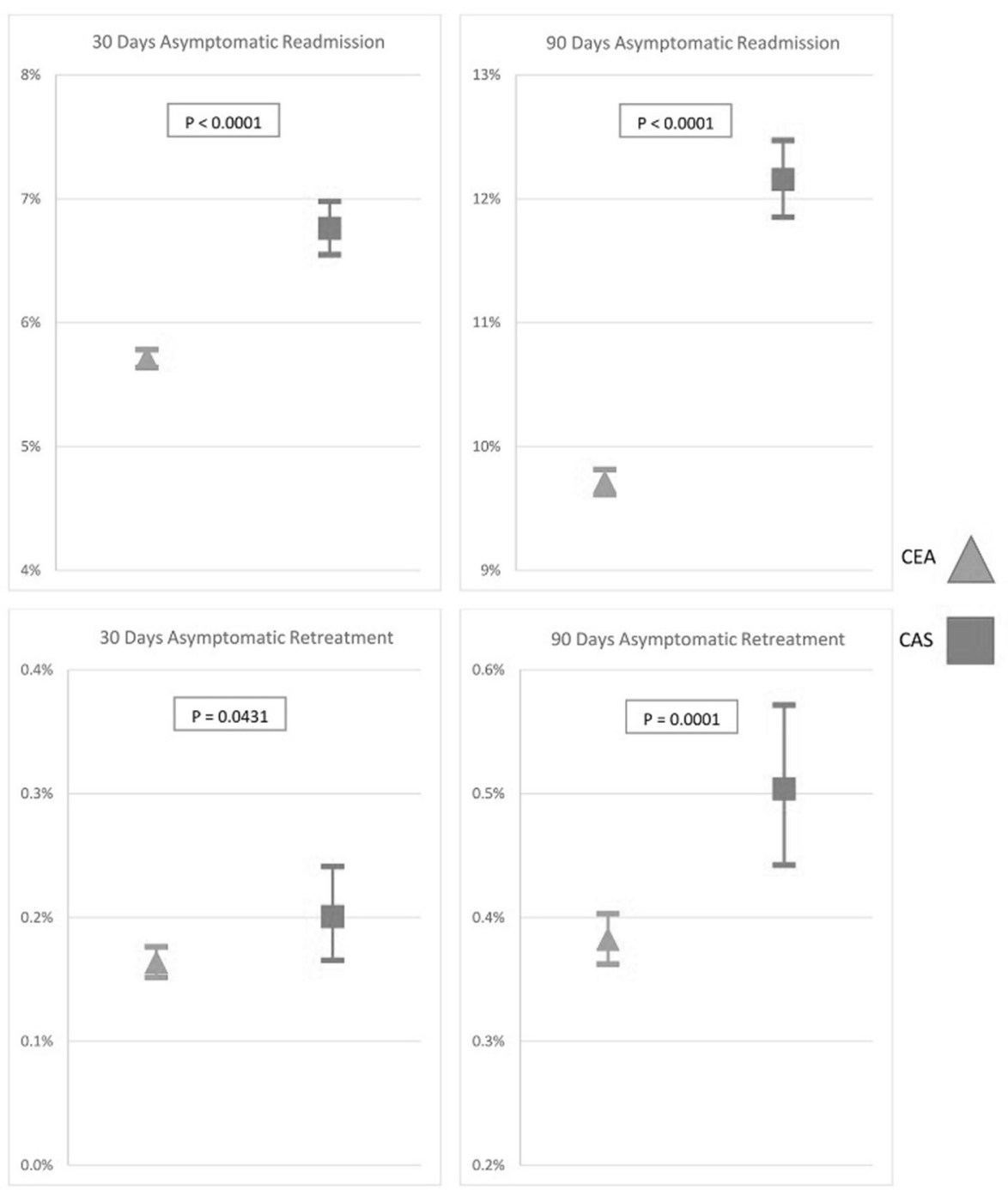

